\title{
Are attempts at regulating flow through systemic-to-pulmonary arterial shunts still valid?
}

\author{
Aditya K. Kaza, MD
}

From the Department of Cardiac Surgery, Boston Children's Hospital, Boston, Mass.

Disclosures: Author has nothing to disclose with regard to commercial support.

Received for publication Aug 14, 2016; accepted for publication Aug 15, 2016; available ahead of print Sept 20, 2016.

Address for reprints: Aditya K. Kaza, MD, Department of Cardiac Surgery, Boston Children's Hospital, 300 Longwood Ave, Bader 273, Boston, MA 02115 (E-mail: Aditya.kaza@cardio.chboston.org).

J Thorac Cardiovasc Surg 2016;152:1353-4

$0022-5223 / \$ 36.00$

Copyright (C) 2016 by The American Association for Thoracic Surgery

http://dx.doi.org/10.1016/j.jtcvs.2016.08.033

Regulation of pulmonary blood flow through systemicto-pulmonary arterial shunts remains an inexact science. This is related to the fact that there are multiple variables that control this blood flow. Neonates who receive these shunts have variable pulmonary vascular resistance, which can alter flow through these shunts. If the shunt is part of a larger operation with significant bypass run, then there are predictable changes in systemic and pulmonary vascular resistance during the perioperative period. The ability to modulate flow through these shunts would be most beneficial during this time, when there are significant perturbations in systemic and pulmonary vascular resistance. There have been various methodologies proposed through the years to help regulate shunt flow. External bands and clips have been used to regulate shunt flow, with variable results. These are crude ways to regulate shunt flow, but there are no accurate methodologies for being precise.

In their article in this issue of the Journal, the Toronto group of Atlin and colleagues ${ }^{1}$ outlines their methodology for calculating the diameter and length of external bands that can be used on standard-diameter shunts to help regulate flow. They validated these calculations in a computational model and then applied it in clinical practice. This innovative article describes their single-institution approach to manipulating shunt diameter to regulate pulmonary blood flow. This problem with regulating blood flow through shunts has been a vexing problem for everyone in congenital heart surgery. The situation is particularly problematic in low-birth weight infants, in whom the 3-mm shunt is prone to thrombosis and the $3.5-\mathrm{mm}$ shunt provides too much pulmonary blood flow. Atlin and colleagues ${ }^{1}$ have developed a formula for applying a polytetrafluoroethylene band externally to manipulate flow through the shunt; the formula was validated in a shunt banding model. This technique was applied in 8 patients with a variety of shunts. Three patients had banding at time of the original operation, whereas the other 5 patients received shunt banding in the intensive care unit. Atlin and colleagues ${ }^{1}$ noted hemodynamic improvement in 5 patients who underwent shunt

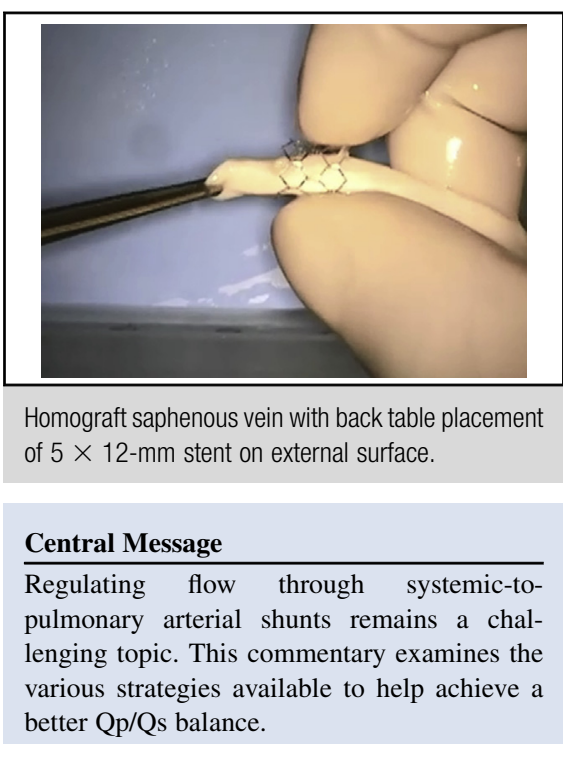

See Article page 1343.

banding. More importantly, there was no shunt thrombosis related to the banding procedure. Atlin and colleagues ${ }^{1}$ have demonstrated that this shunt banding procedure can be done with significant improvement in hemodynamic status. The maintenance of pulmonary-to-systemic flow ratio (Qp/Qs) is, however, multifactorial and related to a wide variety of factors, such as pulmonary vascular resistance and systemic vascular resistance, among others. The current process of one shunt size fits all has been proved to be inaccurate. The article reiterates the fact that the pulmonary blood flow needs to be constantly assessed in the postoperative period to optimize systemic perfusion and oxygen delivery. ${ }^{1}$

At our institution, Boston Children's Hospital, we are exploring alternate strategies to regulating shunt flow. The first concept is the maintenance of low systemic vascular resistance after surgery to maximize oxygen delivery. ${ }^{2} \mathrm{We}$ hypothesized that we could successfully modulate Qp/Qs by varying the systemic vascular resistance. Theoretically, restriction of pulmonary blood flow helps to achieve the desired Qp/Qs value at a point in time. Over the long run, the ability to regulate systemic resistance to help optimize oxygen delivery and thus mitigate the need for manipulating shunt flow seems more attractive. This is especially true for the 3- and 3.5-mm shunts, for which there is a significant risk of shunt thrombosis with manipulation. The second strategy is another shunt modification methodology 


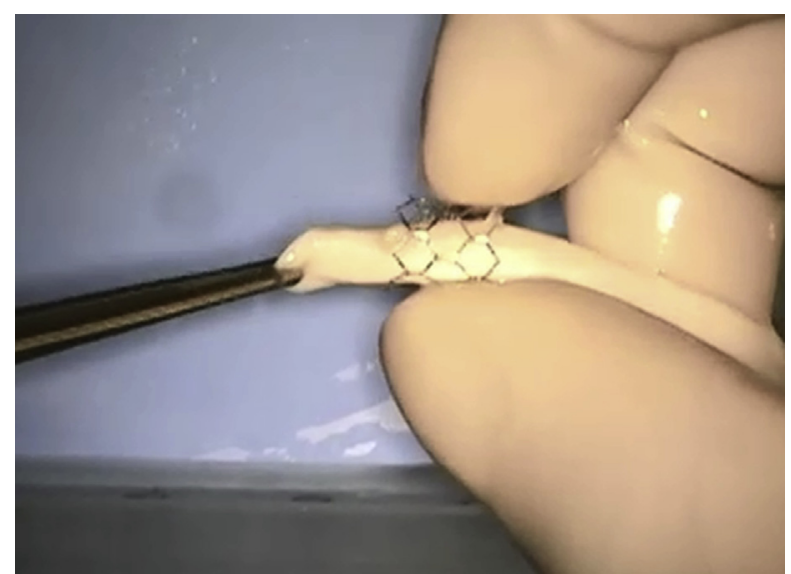

FIGURE 1. Homograft saphenous vein with back table placement of a $5 \times 12-\mathrm{mm}$ stent on the external surface. (Picture courtesy of Dr Sitaram Emani.)

that we have been using at Boston Children's Hospital during the past 2 years. This modification is based on the expandable human venous valve conduit concept. ${ }^{3}$ We use homograft (femoral vein or saphenous vein) shunts with external stent restrictor that can then be expanded or crimped down as needed (Figure 1) to regulate shunt flow.
The challenge, once again, is how tightly to crimp the stent and thus restrict flow through the shunt during the tenuous perioperative period. The main impetus for development of these shunts was the need for more pulmonary blood flow as the child grows. The external stent gives us the ability to increase pulmonary blood flow by dilating the stent in the catheterization laboratory, thus keeping up with somatic growth.

In conclusion, the Toronto group of Atlin and colleagues ${ }^{1}$ has provided us with a validated approach to help regulate shunt flow in critically ill patients. We need, however, to look past this concept of shunt manipulation to regulating other hemodynamic parameters to achieve a better $\mathrm{Qp} / \mathrm{Qs}$ balance.

\section{References}

1. Atlin CR, Haller H, Honjo O, Jegatheeswaran A, Van Arsdell GS. Balancing pulmonary blood flow: theory, in vitro measurements, and clinical correlation of systemic to pulmonary shunt banding. J Thorac Cardiovasc Surg. 2016;152: 1343-52.e2.

2. Li J, Zhang G, McCrindle BW, Holtby H, Humpl T, Cai S, et al. Profiles of hemodynamics and oxygen transport derived by using continuous measured oxygen consumption after the Norwood procedure. J Thorac Cardiovasc Surg. 2007; 133:441-8.

3. Roberts EG, Quinonez L, Piekarski B, Baird CW, Emani SM. Expandable valve for pediatric application constructed from human venous valved conduit within a stent. Ann Thorac Surg. 2015;100:2320-4. 